\title{
Modification on Indacenodithieno[3,2- b]thiophene Core to Achieve Higher Current and Reduced Energy Loss for Nonfullerene Solar Cells
}

Zhuohan Zhang, ${ }^{*} \perp$ Hongtao Wang, ${ }^{,}, \perp$ Jiangsheng Yu, ${ }^{*}, *$ Rui Sun, ${ }^{\S}$ Jinqiu Xu, ${ }^{\epsilon}$ Linqiang Yang, ${ }^{\dagger}$ Renyong Geng,,$^{\dagger}$ Jinru Cao, ${ }^{\dagger}$ Fuqiang Du, ${ }^{\dagger}$ Jie Min, ${ }^{*}$, Feng Liu,,$\epsilon$ and Weihua Tang*, ${ }^{\dagger}$

\section{Table of Content}

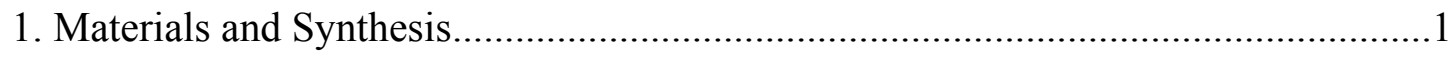

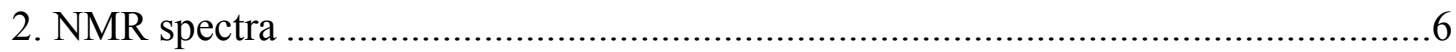

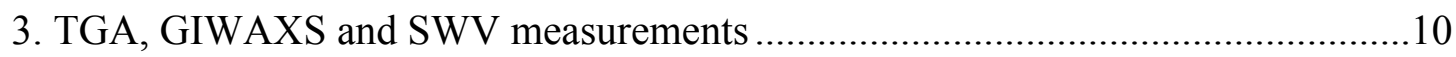

4. SCLC Mobility Measurements. ........................................................................

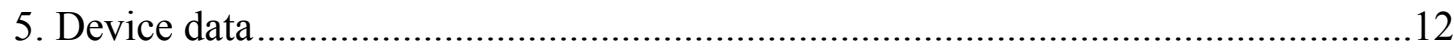

\section{Materials and Synthesis}

All commercially available chemicals and solvents were purchased from Aladdin, Sigma-Aldrich, or J\&K Chemical Co., and used without further purification. Among of them, 2-(5,6-difluoro-3-oxo-2,3-dihydro-1H-inden-1-ylidene) malononitrile was purchased from Derthon Optoelectronic Materials Science Technology Co. LTD., non- 
fullerene IT-4F was purchased from SunaTech Inc., while polymer donor PM6 was purchased from Solarmer Materials Inc.. Compound 1, 4 and 5 were synthesized according to literature. ${ }^{1,2}$ Anhydrous THF and toluene were freshly distilled over sodium wire prior to use. Detailed synthetic processes of IM-4F and IOM-4F are described in the following.
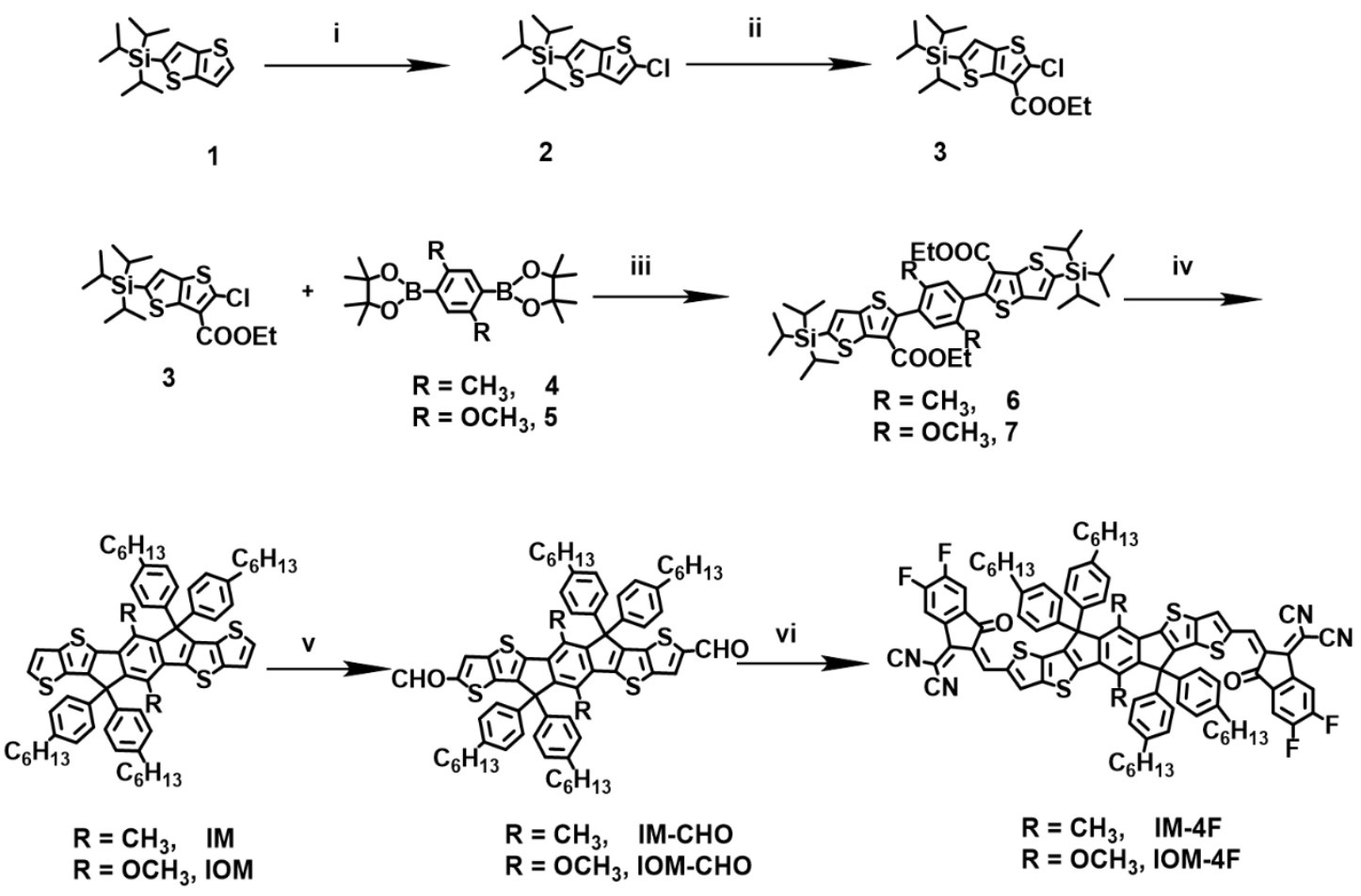

Scheme 1. Synthesis of IM-4F and IOM-4F. Conditions and reagents: (i) NCS, DMF, $50{ }^{\circ} \mathrm{C}$; (ii) a) $\mathrm{TMPMgCl} \cdot \mathrm{LiCl}$, THF, r.t.; b) $\mathrm{CNCOOEt},-40{ }^{\circ} \mathrm{C}$ to r.t.; (iii) $\mathrm{Pd}(\mathrm{OAc})_{2}$, Sphos, $\mathrm{K}_{3} \mathrm{PO}_{4}$, dioxane $/ \mathrm{H}_{2} \mathrm{O}(5 / 1$, v/v), reflux; (iv) a) 1-bromo-4-hexylbenzene, $n$-BuLi, THF, $-78{ }^{\circ} \mathrm{C}$; b) $\mathrm{BF}_{3} \cdot \mathrm{Et}_{2} \mathrm{O}, \mathrm{CH}_{2} \mathrm{Cl}_{2}$, r.t.; c) $\mathrm{N}\left(\mathrm{C}_{4} \mathrm{H}_{9}\right)_{4} \mathrm{~F}$, THF, dark, r.t.; (v) $\mathrm{POCl}_{3}$, DMF, 1,2-dichloroethane, $85{ }^{\circ} \mathrm{C}$; (vi) 2-(5,6-difluoro-3-oxo-2,3-dihydro-1H-inden-1ylidene)malononitrile, pyridine, $\mathrm{CHCl}_{3}, 75^{\circ} \mathrm{C}$.

\section{Compound 6 and 7}

Compound 6 and 7 can be easily synthesized by Suzuki coupling. The general procedure for the synthesis of coupling intermediates was elaborated as follows. An oven-dried two-necked round bottom flask was charged with compound $\mathbf{3}$, compound 4 or $5, \mathrm{~K}_{3} \mathrm{PO}_{4}$, dioxane $(15 \mathrm{~mL})$, and $\mathrm{H}_{2} \mathrm{O}(3 \mathrm{~mL})$, and purged with argon for $20 \mathrm{~min}$. $\mathrm{Pd}(\mathrm{OAc})_{2}$ and Sphos were added subsequently under argon. The resultant mixture was then heated at $110^{\circ} \mathrm{C}$ for $15 \mathrm{~h}$. After cooling to room temperature, the mixture was 
extracted three times with dichloromethane, dried $\left(\mathrm{MgSO}_{4}\right)$ and concentrated in vacuo. The crude product was purified by silica column chromatography, and compound 6 or 7 was obtained.

Diethyl 2,2'-(2,5-dimethyl-1,4-phenylene)bis(5-(triisopropylsilyl)thieno[3,2b] thiophene-3-carboxylate) (6)

Compound 3 (1.69 g, $4.19 \mathrm{mmol})$, compound 4 (0.6 g, $1.68 \mathrm{mmol}), \mathrm{K}_{3} \mathrm{PO}_{4}(1.78 \mathrm{~g}$, $8.38 \mathrm{mmol})$, dioxane $(15 \mathrm{~mL}), \mathrm{H}_{2} \mathrm{O}(3 \mathrm{~mL}), \mathrm{Pd}(\mathrm{OAc})_{2}(75 \mathrm{mg}, 0.34 \mathrm{mmol})$ and Sphos (138 mg, $0.34 \mathrm{mmol}$ ) were used for Suzuki coupling reaction. Compound 6 (1.1 g) was obtained as a white solid in a yield of 65\%. ${ }^{1} \mathrm{H}$ NMR (500 MHz, $\left.\mathrm{CDCl}_{3}\right): \delta 7.38(\mathrm{~s}, 2 \mathrm{H})$, $7.21(\mathrm{~s}, 2 \mathrm{H}), 4.26(\mathrm{q}, J=7.1 \mathrm{~Hz}, 4 \mathrm{H}), 2.23(\mathrm{~s}, 6 \mathrm{H}), 1.41(\mathrm{~h}, J=7.4 \mathrm{~Hz}, 6 \mathrm{H}), 1.21(\mathrm{t}, J$ $=7.1 \mathrm{~Hz}, 6 \mathrm{H}), 1.16(\mathrm{~d}, J=7.4 \mathrm{~Hz}, 36 \mathrm{H}) .{ }^{13} \mathrm{C} \mathrm{NMR}\left(125 \mathrm{MHz}, \mathrm{CDCl}_{3}\right): \delta 162.34,152.72$, $145.00,139.13,138.28,134.68,134.52,131.62,126.59,122.39,61.03,19.86,18.88$, 14.15, 12.08. HRMS (ESI) $m / z:[\mathrm{M}+\mathrm{H}]^{+}$calcd for $\mathrm{C}_{44} \mathrm{H}_{62} \mathrm{O}_{4} \mathrm{~S}_{4} \mathrm{Si}_{2}, 838.3069$; found, 843.6483.

Diethyl 2,2'-(2,5-dimethoxy-1,4-phenylene)bis(5-(triisopropylsilyl)thieno[3,2b] thiophene-3-carboxylate) (7)

Compound 3 (1.55 g, $3.85 \mathrm{mmol})$, compound 5 (0.6 g, $1.54 \mathrm{mmol}), \mathrm{K}_{3} \mathrm{PO}_{4}(1.63 \mathrm{~g}$, $7.69 \mathrm{mmol})$, dioxane $(15 \mathrm{~mL}), \mathrm{H}_{2} \mathrm{O}(3 \mathrm{~mL}), \mathrm{Pd}(\mathrm{OAc})_{2}(69 \mathrm{mg}, 0.31 \mathrm{mmol})$ and Sphos (126 mg, $0.31 \mathrm{mmol})$ were used for Suzuki coupling reaction. Compound 6 (0.7 g) was obtained as a white solid in a yield of 45\%. ${ }^{1} \mathrm{H}$ NMR (500 MHz, $\left.\mathrm{CDCl}_{3}\right): \delta 7.38(\mathrm{~s}, 2 \mathrm{H})$, $6.98(\mathrm{~s}, 2 \mathrm{H}), 4.29$ (q, $J=7.2 \mathrm{~Hz}, 4 \mathrm{H}), 3.75(\mathrm{~s}, 6 \mathrm{H}), 1.41(\mathrm{p}, J=7.4 \mathrm{~Hz}, 6 \mathrm{H}), 1.25$ (t, $J$ $=7.1 \mathrm{~Hz}, 6 \mathrm{H}), 1.16(\mathrm{~d}, J=7.5 \mathrm{~Hz}, 32 \mathrm{H}) .{ }^{13} \mathrm{C} \mathrm{NMR}\left(125 \mathrm{MHz}, \mathrm{CDCl}_{3}\right): \delta 157.17,145.31$, $142.54,139.75,133.65,132.94,121.12,119.26,117.56,109.15,55.46,50.95,13.34$, 8.79, 6.54. HRMS (ESI) $m / z$ : $[\mathrm{M}+\mathrm{H}]^{+}$calcd for $\mathrm{C}_{44} \mathrm{H}_{62} \mathrm{O}_{6} \mathrm{~S}_{4} \mathrm{Si}_{2}, 870.2968$; found, 870.2964 .

\section{Compound IM and IOM}

To a solution of 4-hexyl-1-bromobenzene $(1.12,4.65 \mathrm{mmol})$ in THF $(25 \mathrm{~mL})$ at $78{ }^{\circ} \mathrm{C}$ was added $n$-BuLi (1.72 $\mathrm{mL}, 4.29 \mathrm{mmol}, 2.5 \mathrm{M}$ in hexane) and the mixture was kept at $-78^{\circ} \mathrm{C}$ for $1 \mathrm{~h}$. A solution of compound 6 or $7(0.6 \mathrm{~g})$ in THF $(15 \mathrm{~mL})$ was then 
added slowly. The mixture was stirred at room temperature overnight, then poured into water and extracted twice with ethyl acetate. The combined organic layer was dried over $\mathrm{MgSO}_{4}$. After removal of the solvent under reduced pressure, the residue was dissolved in anhydrous dichloromethane $(30 \mathrm{~mL})$, then several drops of $\mathrm{BF}_{3} \cdot \mathrm{Et}_{2} \mathrm{O}$ was added slowly. The resulting solution was stirred at room temperature for $3 \mathrm{~h}$ and then quenched with water. The organic layer was washed with water for three times and extracted with petroleum ether $(3 \times 50 \mathrm{~mL})$. The combined organic phase was dried over anhydrous $\mathrm{MgSO}_{4}$. Then, the crude products were obtained by flash column chromatography on silica gel. Then, the deprotection reaction was followed. Tetrabutylammonium fluoride trihydrate $(2.84 \mathrm{~mL}, 1 \mathrm{M}$ in THF, $2.84 \mathrm{mmol})$ was added to the intermediates in THF $(30 \mathrm{~mL})$. The reaction mixture was stirred for $16 \mathrm{~h}$ in the absence of light. The organic layer was washed with water for three times and extracted with petroleum ether $(3 \times 50 \mathrm{~mL})$. The combined organic phase was dried over anhydrous $\mathrm{MgSO}_{4}$. Then, the crude products were purified by column chromatography on silica gel using petroleum ether/ dichloromethane $(10: 1, \mathrm{v} / \mathrm{v})$ to give a light yellow solid.

\section{Compound IM}

According to the above description, compound IM (0.56 g) was synthesized in a yield of 75\%. ${ }^{1} \mathrm{H}$ NMR (500 MHz, $\mathrm{CDCl}_{3}$ ): $\delta 7.28$ (d, $\left.J=8.0 \mathrm{~Hz}, 8 \mathrm{H}\right), 7.22$ (d, $J=5.2$ $\mathrm{Hz}, 2 \mathrm{H}), 7.18(\mathrm{~d}, J=5.2 \mathrm{~Hz}, 2 \mathrm{H}), 7.08(\mathrm{~d}, J=8.0 \mathrm{~Hz}, 8 \mathrm{H}), 2.56(\mathrm{t}, J=7.9 \mathrm{~Hz}, 8 \mathrm{H})$, $2.28(\mathrm{~s}, 6 \mathrm{H}), 1.58(\mathrm{t}, J=7.7 \mathrm{~Hz}, 8 \mathrm{H}), 1.34-1.24(\mathrm{~m}, 24 \mathrm{H}), 0.89-0.82(\mathrm{~m}, 12 \mathrm{H}) .{ }^{13} \mathrm{C}$ NMR (125 MHz, $\left.\mathrm{CDCl}_{3}\right): \delta 146.51,142.41,137.21,137.18,136.26,131.59,131.25$, $127.79,123.48,122.86,120.52,120.36,114.75,57.79,30.31,26.44,25.97,23.89$, 17.32, 11.72. HRMS (ESI) $\mathrm{m} / \mathrm{z}:[\mathrm{M}+\mathrm{H}]^{+}$calcd for $\mathrm{C}_{70} \mathrm{H}_{78} \mathrm{~S}_{4}, 1046.4986$; found, 1046.4979 .

\section{Compound IOM}

According to the above description, compound IOM $(0.32 \mathrm{~g})$ was synthesized in a yield of 47\%. ${ }^{1} \mathrm{H}$ NMR $\left(500 \mathrm{MHz}, \mathrm{CDCl}_{3}\right): \delta 7.30(\mathrm{~d}, J=8.2 \mathrm{~Hz}, 2 \mathrm{H}), 7.26-7.21(\mathrm{~m}$, 
$1 \mathrm{H}), 7.10(\mathrm{~d}, J=8.0 \mathrm{~Hz}, 2 \mathrm{H}), 3.23(\mathrm{~s}, 1 \mathrm{H}), 2.57(\mathrm{t}, J=7.8 \mathrm{~Hz}, 2 \mathrm{H}), 1.58(\mathrm{dd}, J=10.8$, $5.1 \mathrm{~Hz}, 2 \mathrm{H}), 1.36-1.24(\mathrm{~m}, 6 \mathrm{H}), 0.90-0.83(\mathrm{~m}, 3 \mathrm{H}) .{ }^{13} \mathrm{C} \mathrm{NMR}\left(125 \mathrm{MHz}, \mathrm{CDCl}_{3}\right): \delta$ $142.01,141.66,141.09$, 137.76, 136.50, 133.97, 132.50, 127.87, 126.38, 123.44, $122.92,121.03,114.87,58.05,55.91,30.29,26.43,25.99,23.78,17.32,8.80$. HRMS (ESI) $m / z:[\mathrm{M}+\mathrm{H}]^{+}$calcd for $\mathrm{C}_{70} \mathrm{H}_{78} \mathrm{O}_{2} \mathrm{~S}_{4}, 1078.4885$; found, 1079.4954 .

\section{Compound IM-CHO and IOM-CHO}

To a solution of compound IM or IOM in dry $8 \mathrm{~mL}$ 1,2-dichloroethane $\left(\mathrm{ClCH}_{2} \mathrm{CH}_{2} \mathrm{Cl}\right)$ and $3 \mathrm{~mL}$ DMF was dropped $0.6 \mathrm{~mL}$ of phosphorus oxychloride $\left(\mathrm{POCl}_{3}\right)$ at $0{ }^{\circ} \mathrm{C}$ under the protection of nitrogen. The mixture was stirred at $0{ }^{\circ} \mathrm{C}$ for $0.5 \mathrm{~h}$. After refluxing at $85{ }^{\circ} \mathrm{C}$ overnight, the mixture was poured into ice water $(100 \mathrm{~mL})$, neutralized with saturated sodium hydroxide solution, and then extracted with ethyl acetate twice. The combined organic layer was washed with water and brine, dried over $\mathrm{MgSO}_{4}$, and evaporated under reduced pressure. The crude product was purified by silica gel using petroleum ether/dichloromethane $(2: 1, \mathrm{v} / \mathrm{v})$ as eluent, yielding a yellow solid.

\section{Compound IM-CHO}

According to the above description, compound IM-CHO (0.49 g) was synthesized in a yield of $83 \% .{ }^{1} \mathrm{H}$ NMR (500 MHz, $\left.\mathrm{CDCl}_{3}\right): \delta 9.84(\mathrm{~s}, 2 \mathrm{H}), 7.88(\mathrm{~s}, 2 \mathrm{H}), 7.24(\mathrm{~d}, J$ $=8.1 \mathrm{~Hz}, 8 \mathrm{H}), 7.11(\mathrm{~d}, J=8.1 \mathrm{~Hz}, 8 \mathrm{H}), 2.57(\mathrm{t}, J=7.9 \mathrm{~Hz}, 8 \mathrm{H}), 2.32(\mathrm{~s}, 6 \mathrm{H}), 1.59(\mathrm{t}, J$ $=7.6 \mathrm{~Hz}, 8 \mathrm{H}), 1.35-1.26(\mathrm{~m}, 24 \mathrm{H}), 0.89-0.83(\mathrm{~m}, 12 \mathrm{H}) .{ }^{13} \mathrm{C} \mathrm{NMR}\left(125 \mathrm{MHz}, \mathrm{CDCl}_{3}\right)$ : $\delta 183.10,153.36,149.08,148.62,143.97,142.81,142.42,139.67,137.63,135.59$, $129.79,128.77,128.70,127.49,63.40,35.80,31.93,31.45,29.37,22.81,17.25,14.31$. HRMS (ESI) $m / z$ : $[\mathrm{M}+\mathrm{H}]^{+}$calcd for $\mathrm{C}_{72} \mathrm{H}_{78} \mathrm{O}_{2} \mathrm{~S}_{4}, 1102.4885$; found, 1102.4880 .

\section{Compound IOM-CHO}

According to the above description, compound IOM-CHO $(0.26 \mathrm{~g})$ was synthesized in a yield of $82 \% .{ }^{1} \mathrm{H}$ NMR $\left(500 \mathrm{MHz}, \mathrm{CDCl}_{3}\right): \delta 9.86(\mathrm{~s}, 2 \mathrm{H}), 7.90(\mathrm{~s}, 2 \mathrm{H}), 7.24(\mathrm{~d}, J$ $=8.1 \mathrm{~Hz}, 8 \mathrm{H}), 7.12(\mathrm{~d}, J=8.1 \mathrm{~Hz}, 8 \mathrm{H}), 3.25(\mathrm{~s}, 6 \mathrm{H}), 2.57(\mathrm{t}, J=7.8 \mathrm{~Hz}, 8 \mathrm{H}), 1.57(\mathrm{~d}$, $J=5.6 \mathrm{~Hz}, 8 \mathrm{H}), 1.32-1.23(\mathrm{~m}, 24 \mathrm{H}), 0.88-0.84(\mathrm{~m}, 12 \mathrm{H}) .{ }^{13} \mathrm{C}$ NMR $(125 \mathrm{MHz}$, 
$\left.\mathrm{CDCl}_{3}\right): \delta 177.59,143.25,142.29,141.86,140.17,138.99,137.77,137.12,134.20$, 131.38, 127.19, 124.31, 123.22, 58.20, 56.24, 30.26, 26.39, 25.96, 23.76, 17.29, 8.78. HRMS (ESI) $m / z$ : [M+H] $]^{+}$calcd for $\mathrm{C}_{72} \mathrm{H}_{78} \mathrm{O}_{4} \mathrm{~S}_{4}, 1134.4783$; found, 1135.4825 .

\section{NMR spectra}

$\stackrel{\text { ำ }}{\stackrel{\sim}{\sim}}$

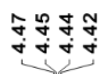

管
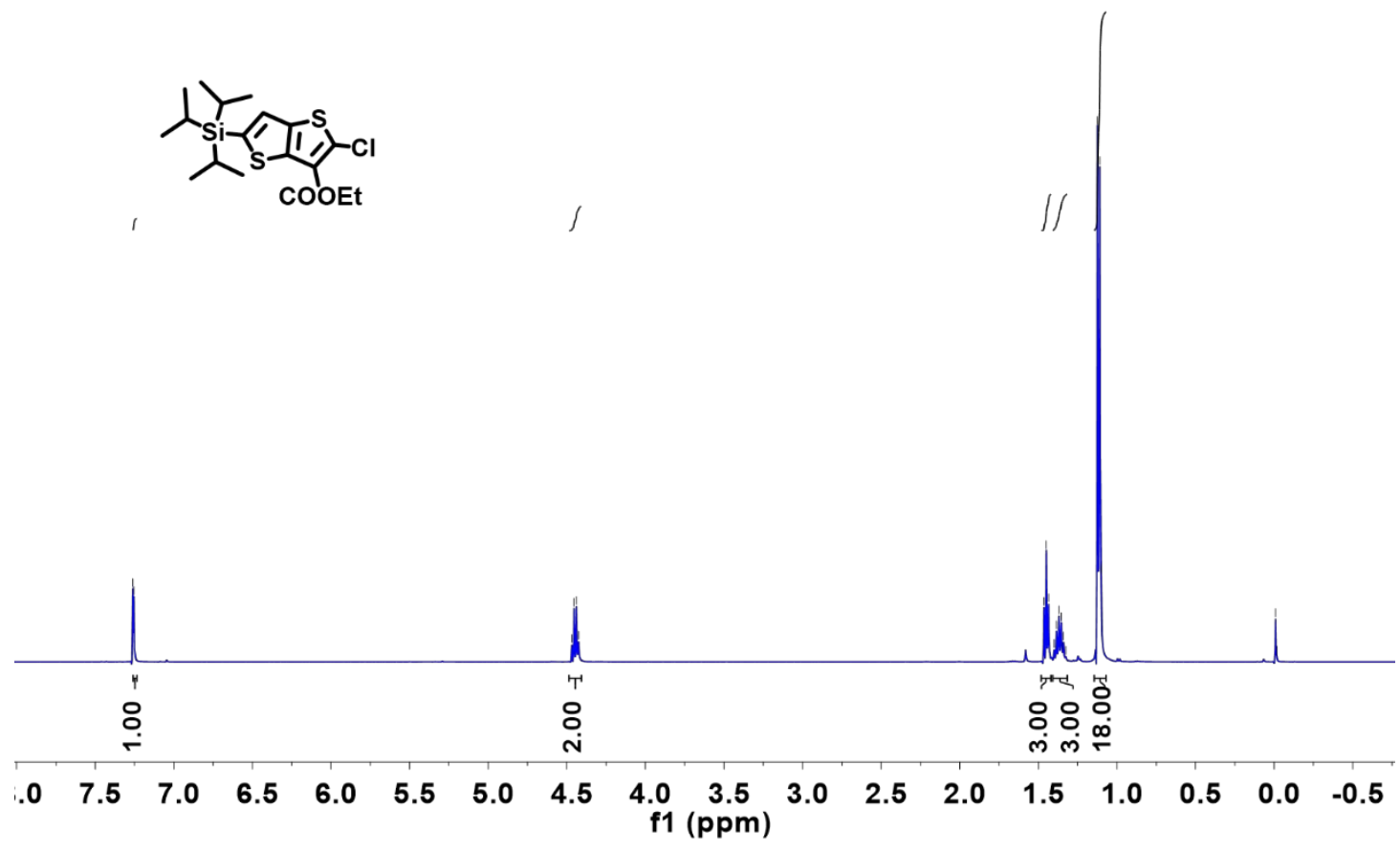

Figure S1. ${ }^{1} \mathrm{H}$ NMR of compound 3. 


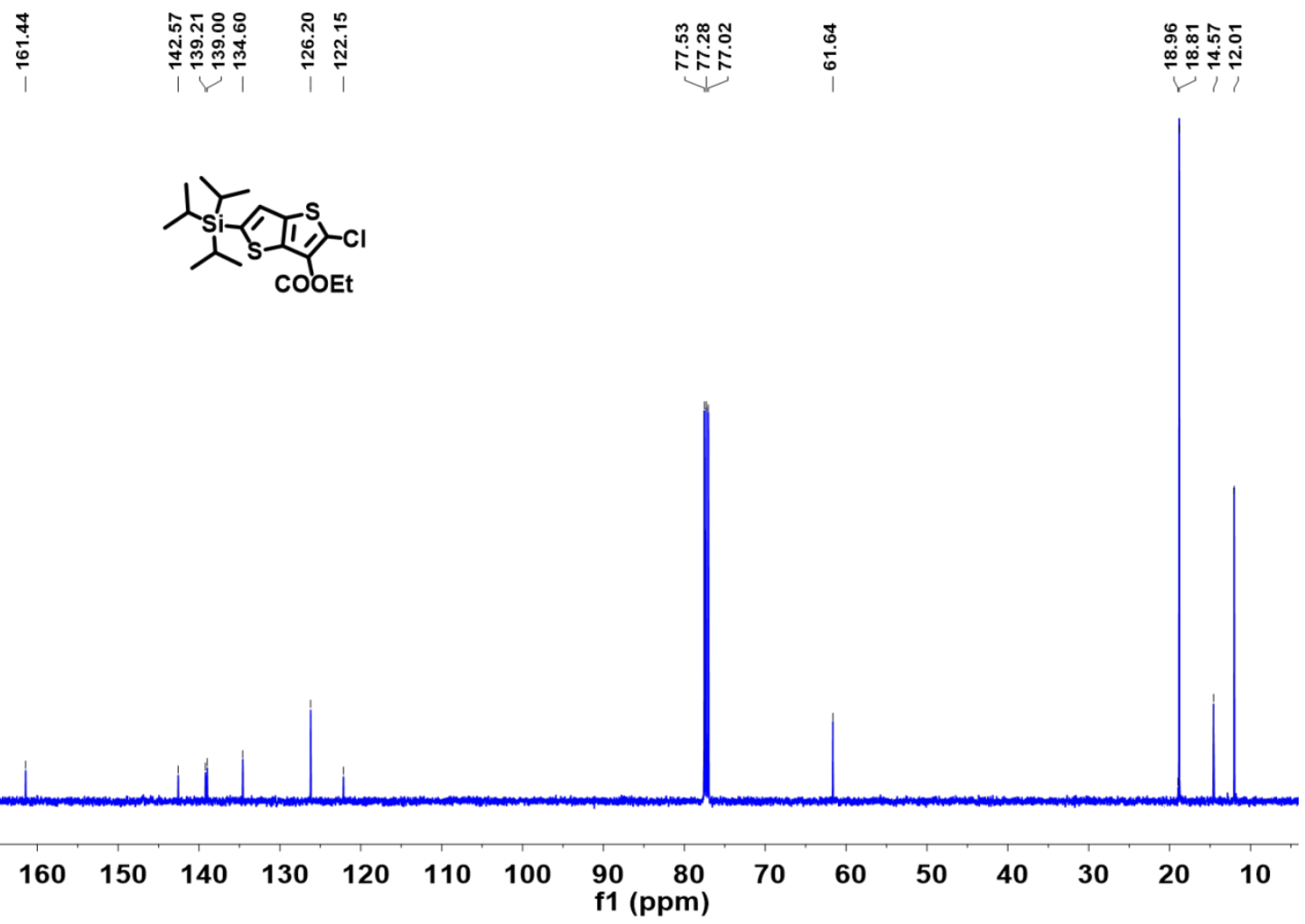

Figure S2. ${ }^{13} \mathrm{C}$ NMR of compound 3 .

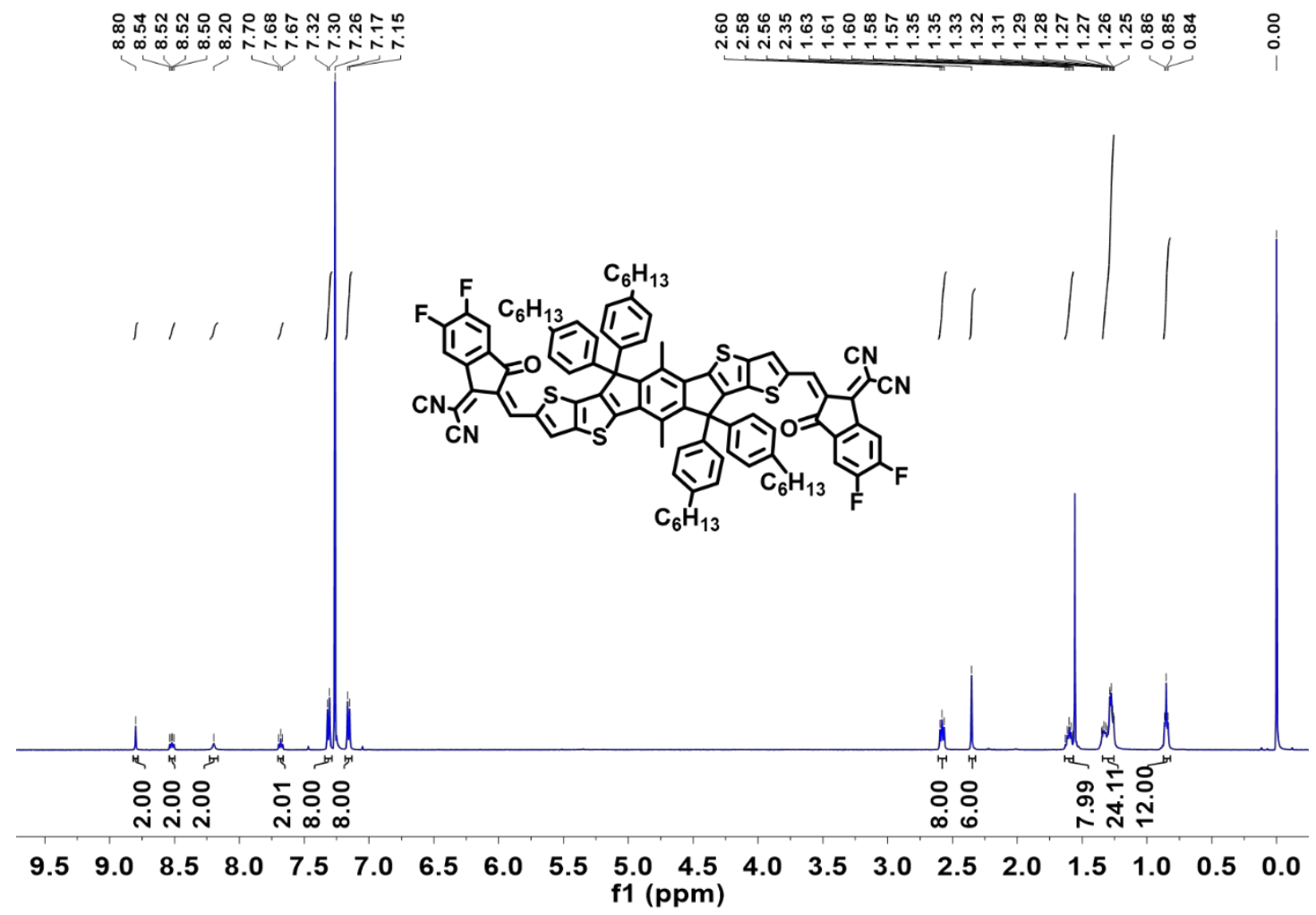

Figure S3. ${ }^{1} \mathrm{H}$ NMR of IM-4F. 


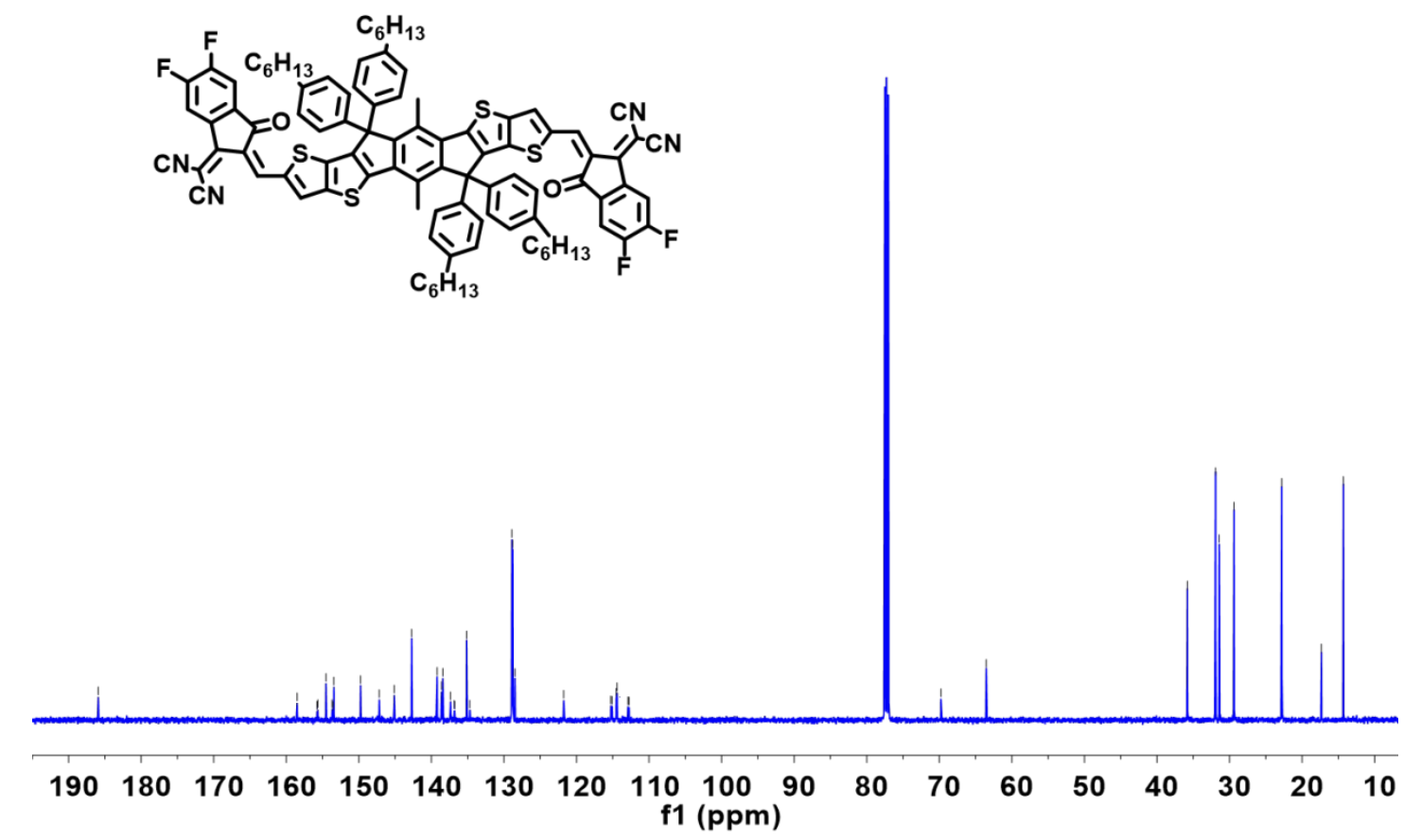

Figure S4. ${ }^{13} \mathrm{C}$ NMR of IM-4F.

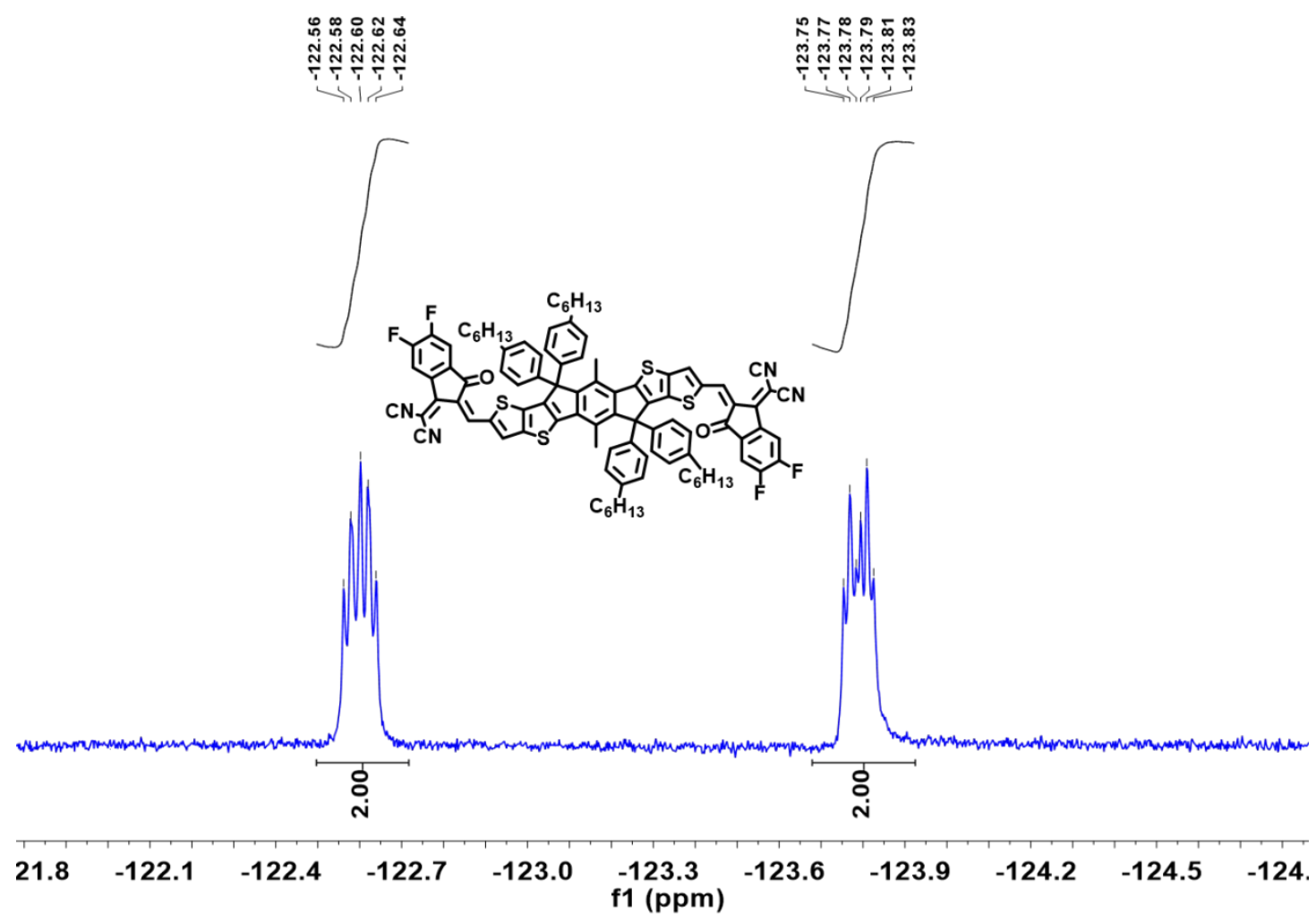

Figure S5. ${ }^{19} \mathrm{~F}$ NMR of IM-4F. 


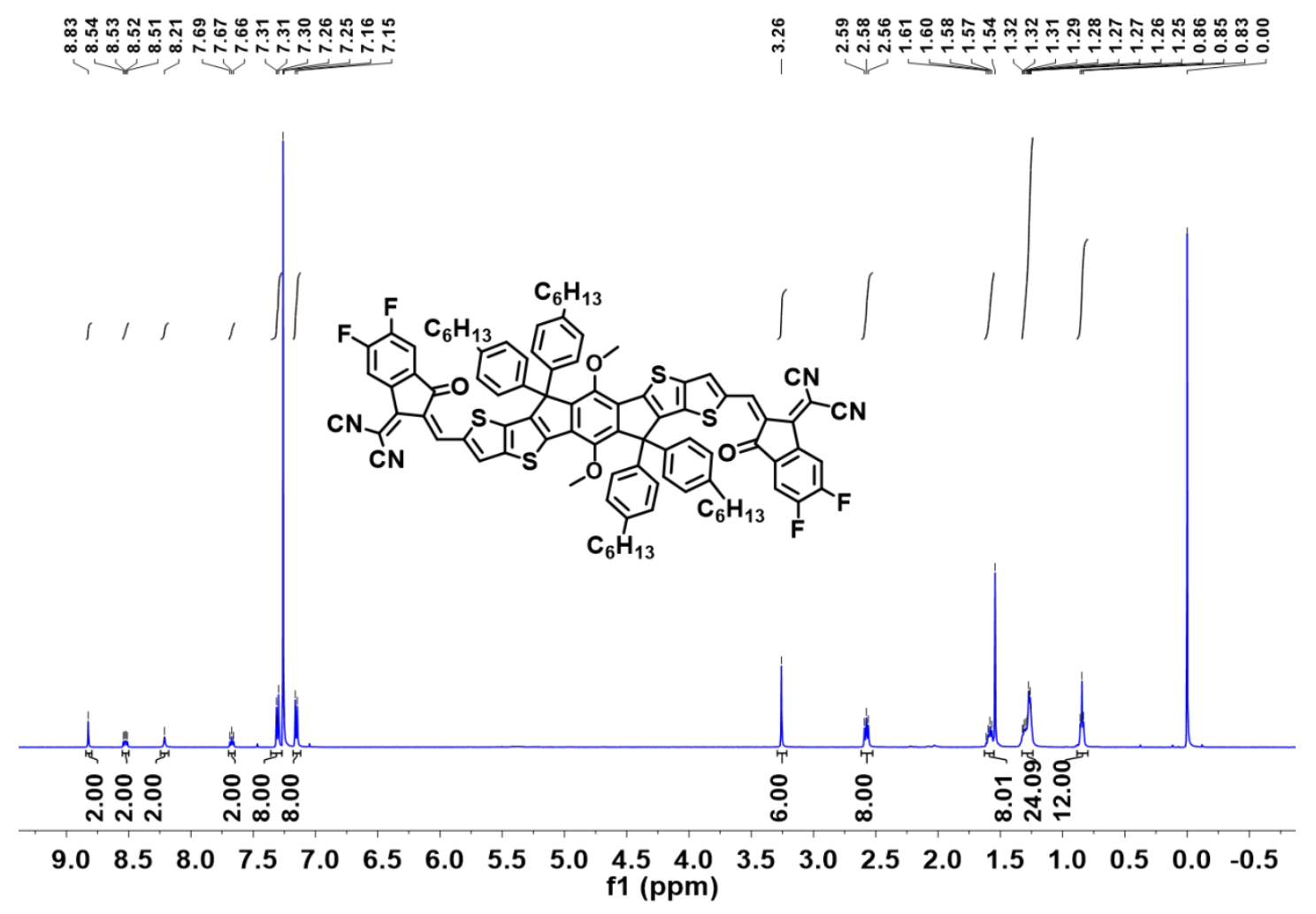

Figure S6. ${ }^{1} \mathrm{H}$ NMR of IOM-4F.

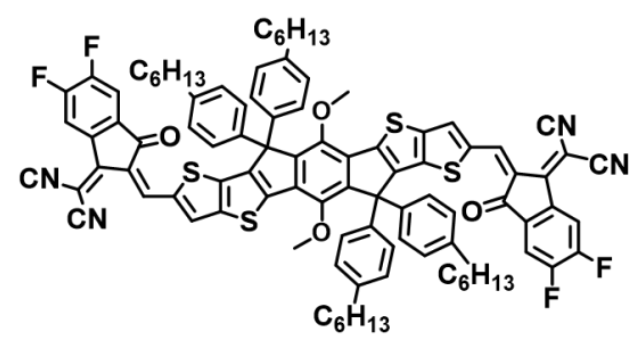

$\begin{array}{llllllllllllllllll}180 & 170 & 160 & 150 & 140 & 130 & 120 & 110 & 100 \underset{\mathrm{f} 1(\mathrm{ppm})}{90} & 80 & 70 & 60 & 50 & 40 & 30 & 20 & 10 & 0\end{array}$

Figure S7. ${ }^{13} \mathrm{C}$ NMR of IOM-4F. 


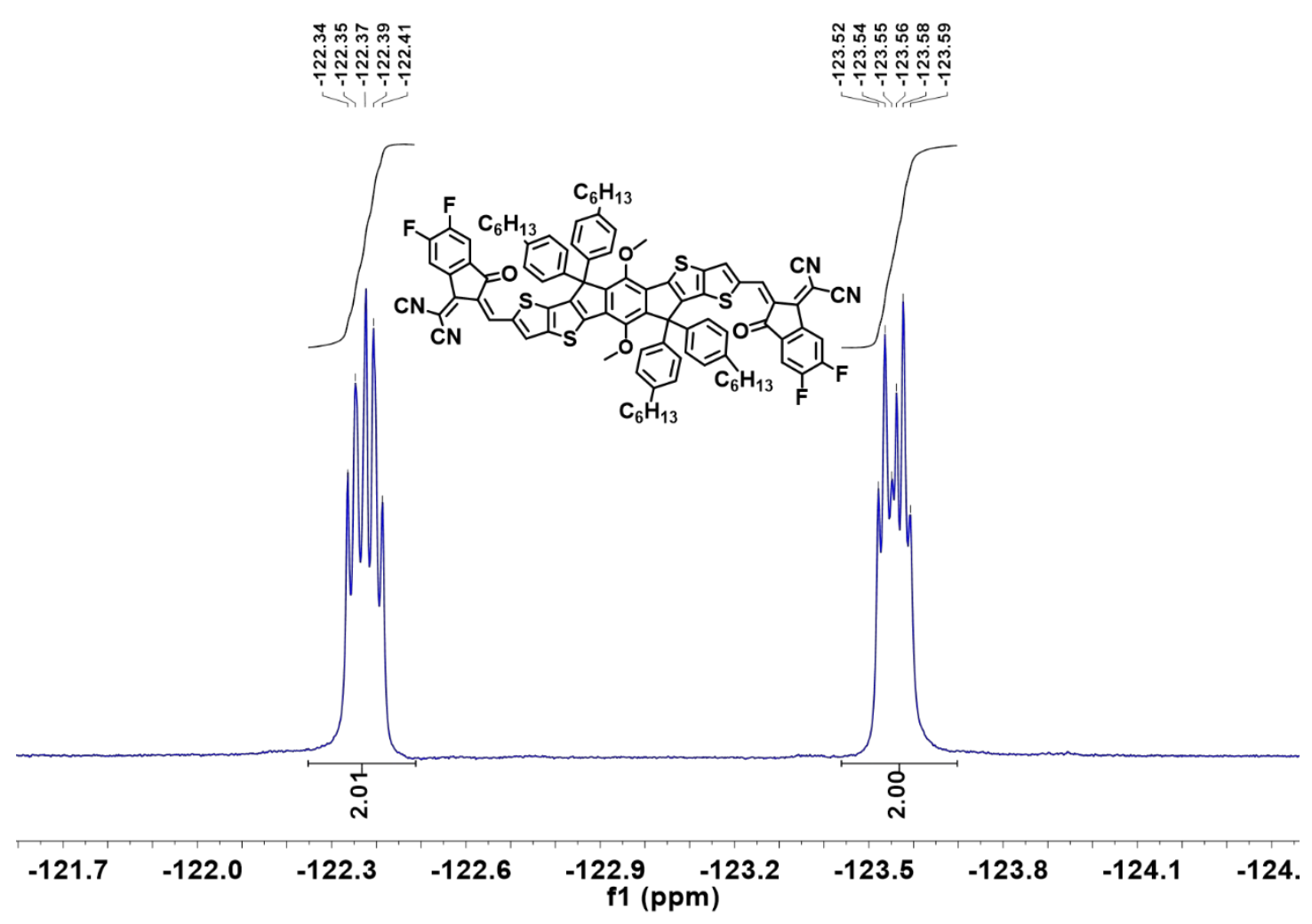

Figure S8. ${ }^{19} \mathrm{~F}$ NMR of IOM-4F.

\section{TGA, GIWAXS and SWV measurements}

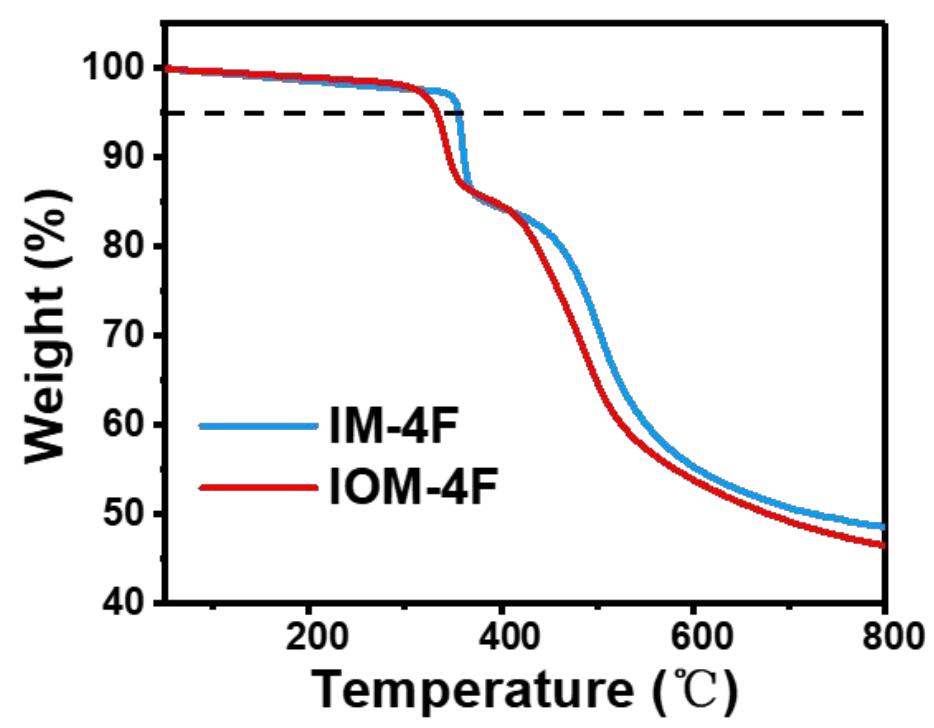

Figure S9. TGA curve of IM-4F and IOM-4F. 

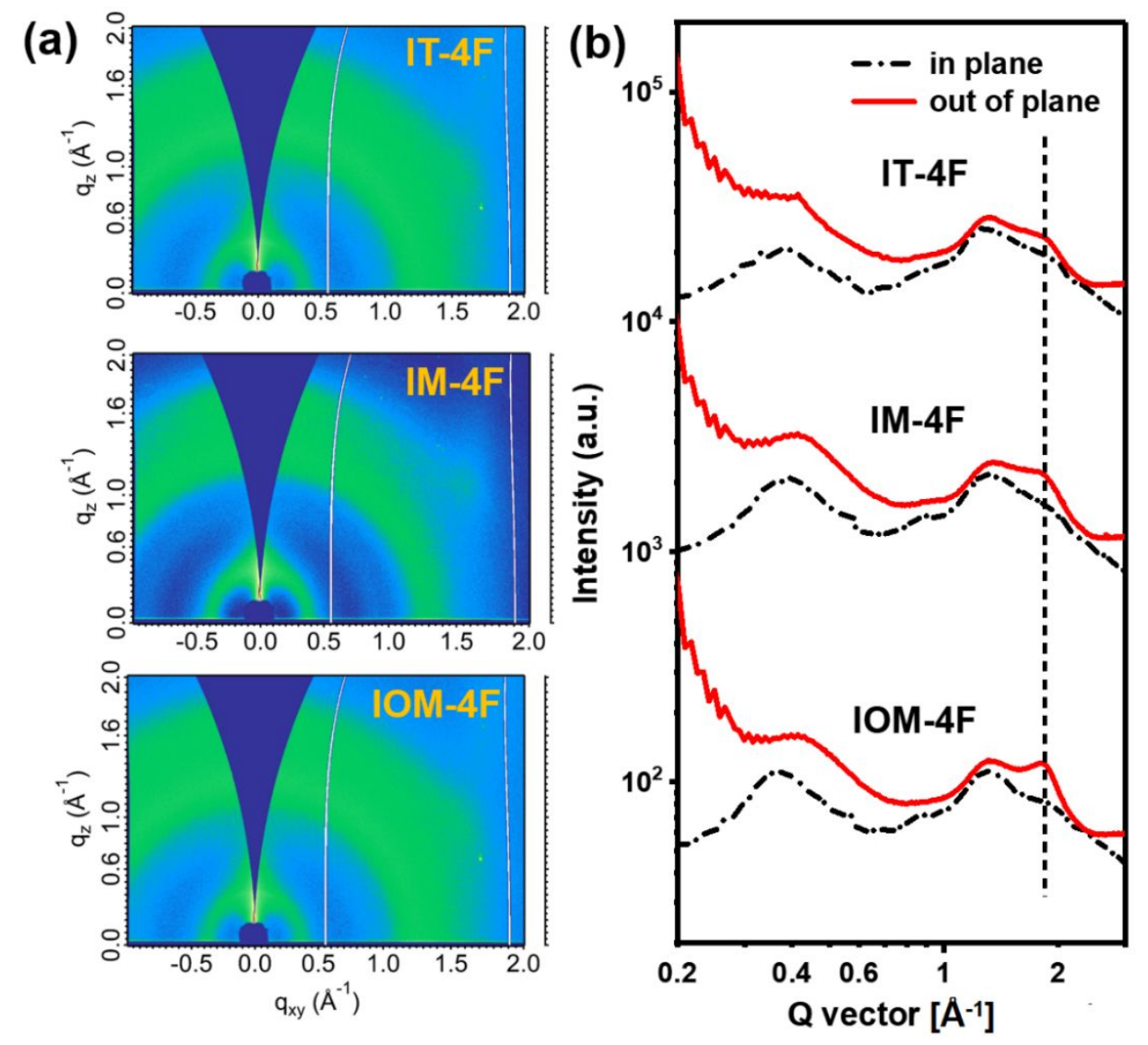

Figure S10. a) GIWAXS patterns of IT-4F, IM-4F, and IOM-4F neat films; b) the related in-plane (black dashed lines) and out-of-plane (red solid lines) line cuts.
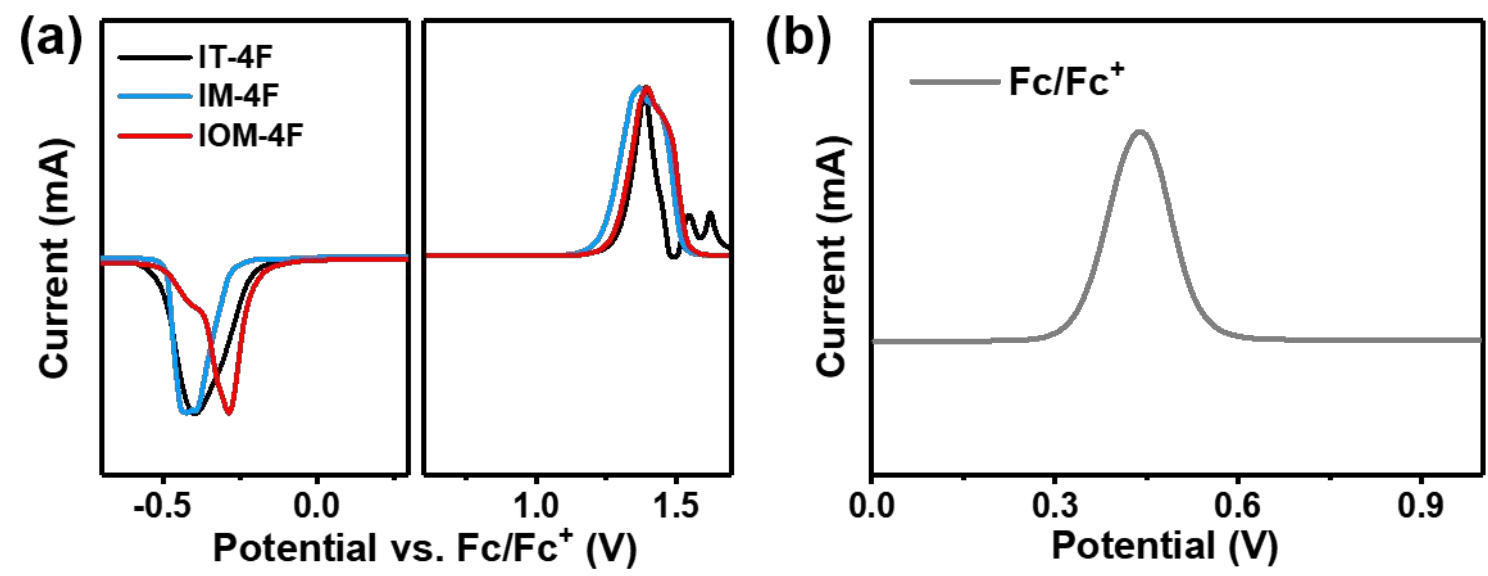

Figure S11. SWV curve of (a) IT-4F, IM-4F, IOM-4F, and (b) ferrocene/ferrocenium. 


\section{SCLC Mobility Measurements}

Electron-only devices with the configuration of ITO/ZnO/active layer/PDINO/Al and hole-only devices with the configuration of ITO/PEDOT:PSS/active layer $/ \mathrm{MoO}_{3} / \mathrm{Ag}$ were used to evaluate charge mobilities by SCLC model. The fabrication conditions of the active layer followed the same procedure described in the above experimental section. The charge mobilities were determined by fitting the dark current according to the following equation:

$$
J=\frac{9}{8} \varepsilon_{r} \varepsilon_{0} \mu \frac{V^{2}}{L^{3}}
$$

where $J$ is the dark current density $\left(\mathrm{mA} \mathrm{cm}^{-2}\right), \varepsilon_{r}$ is the permittivity of free space, $\varepsilon_{0}$ is the dielectric constant of the blend material, $V$ is the effective voltage and $L$ is the thickness of the active layer.

\section{Device data}

Table S1. The optimized photovoltaic parameters of devices based on PM6:IM-4F with different $\mathrm{D} / \mathrm{A}$ ratios.

\begin{tabular}{ccccc}
\hline $\mathrm{D} / \mathrm{A}$ & $V_{\mathrm{OC}}[\mathrm{V}]$ & $J_{\mathrm{SC}}\left[\mathrm{mA} \mathrm{cm}^{-2}\right]$ & $\mathrm{FF}[\%]$ & $\mathrm{PCE}$ a) $[\%]$ \\
\hline \multirow{2}{*}{$1: 0.8$} & 0.92 & 18.75 & 63.40 & 10.94 \\
& $(0.92 \pm 0.01)$ & $(18.34 \pm 0.36)$ & $(62.86 \pm 0.56)$ & $(10.85 \pm 0.06)$ \\
$\mathbf{1 : 1}$ & $\mathbf{0 . 8 9}$ & $\mathbf{1 9 . 4 6}$ & $\mathbf{6 6 . 3 2}$ & $\mathbf{1 1 . 4 9}$ \\
& $\mathbf{( 0 . 8 9} \pm \mathbf{0 . 0 1 )}$ & $\mathbf{( 1 9 . 1 2} \pm \mathbf{0 . 3 2})$ & $\mathbf{( 6 5 . 8 5} \pm \mathbf{0 . 4 5 )}$ & $\mathbf{( 1 1 . 3 2} \pm \mathbf{0 . 1 5 )}$ \\
$1: 1.2$ & 0.89 & 19.03 & 62.77 & 10.63 \\
& $(0.89 \pm 0.01)$ & $(18.64 \pm 0.37)$ & $(62.14 \pm 0.49)$ & $(10.52 \pm 0.13)$ \\
\hline
\end{tabular}

a) The average values were obtained from 12 devices.

Table S2. The optimized photovoltaic parameters of devices based on PM6:IM-4F $=1: 1$ using different additives. 


\begin{tabular}{ccccc}
\hline Additive & $V_{\mathrm{OC}}[\mathrm{V}]$ & $J_{\mathrm{SC}}\left[\mathrm{mA} \mathrm{cm}^{-2}\right]$ & $\mathrm{FF}[\%]$ & $\mathrm{PCE}{ }^{\mathrm{a}}[\%]$ \\
\hline \multirow{2}{*}{ none } & 0.89 & 19.46 & 66.32 & 11.49 \\
& $(0.89 \pm 0.01)$ & $(19.12 \pm 0.32)$ & $(65.85 \pm 0.45)$ & $(11.32 \pm 0.15)$ \\
$\mathbf{0 . 5 \%}$ DIO & $\mathbf{0 . 8 9}$ & $\mathbf{2 1 . 0 4}$ & $\mathbf{6 7 . 7 8}$ & $\mathbf{1 2 . 6 9}$ \\
& $\mathbf{( 0 . 8 9} \pm \mathbf{0 . 0 1})$ & $\mathbf{( 2 0 . 7 2} \pm \mathbf{0 . 3 8})$ & $\mathbf{( 6 7 . 2 4} \pm \mathbf{0 . 5 1 )}$ & $\mathbf{( 1 2 . 4 8} \pm \mathbf{0 . 1 2})$ \\
$1.0 \%$ DIO & 0.85 & 19.31 & 72.25 & 11.86 \\
& $(0.85 \pm 0.01)$ & $(18.99 \pm 0.34)$ & $(71.84 \pm 0.46)$ & $(11.71 \pm 0.13)$ \\
$0.5 \%$ CN & 0.86 & 19.24 & 68.03 & 11.26 \\
& $(0.86 \pm 0.00)$ & $(18.86 \pm 0.29)$ & $(67.65 \pm 0.39)$ & $(11.11 \pm 0.09)$ \\
\hline
\end{tabular}

a) The average values were obtained from over 12 devices.

(a)

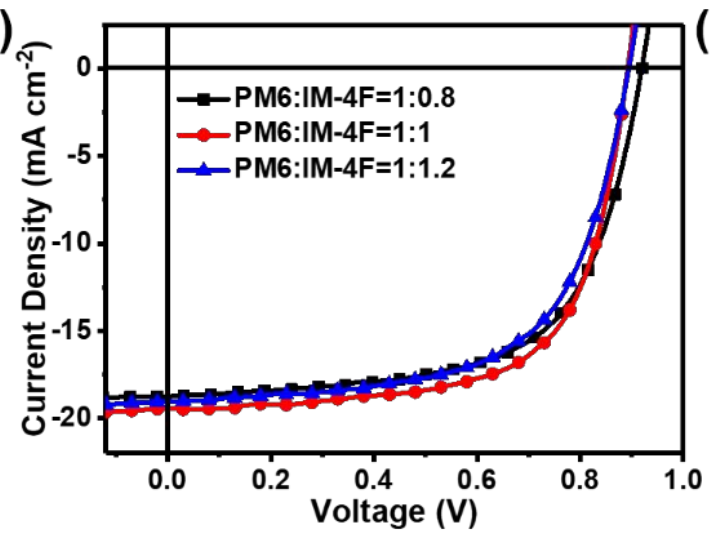

(b)

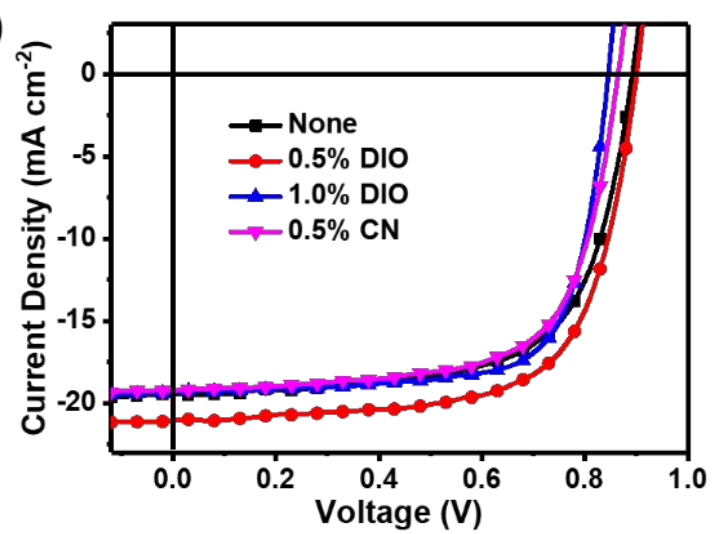

Figure S12. a) $J-V$ curves of PM6:IM-4F based devices with different D/A ratios; b) $J-V$ curves of devices based on $\mathrm{PM} 6: \mathrm{IM}-4 \mathrm{~F}=1: 1$ films with different additives.

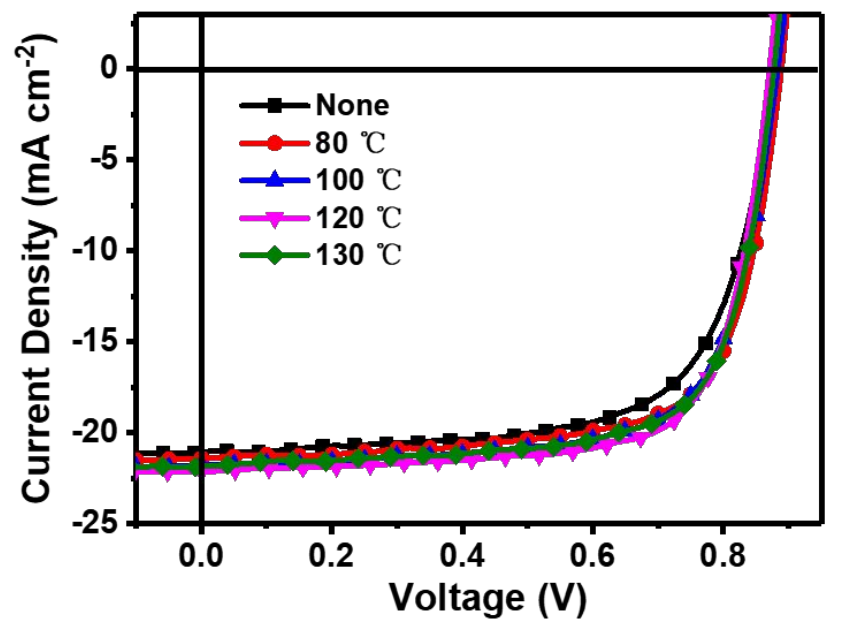

Figure S13. $J-V$ curves of devices based on PM6:IM-4F $=1: 1$ at different thermal annealing temperature with $0.5 \%$ volume DIO. 
Table S3. The optimized photovoltaic parameters of devices based on PM6:IM-4F $=1: 1$ using different thermal annealing temperatures (TATs) with $0.5 \%$ volume DIO.

\begin{tabular}{ccccc}
\hline TAT $\left({ }^{\circ} \mathrm{C}\right)$ & $V_{\mathrm{OC}}[\mathrm{V}]$ & $J_{\mathrm{SC}}\left[\mathrm{mA} \mathrm{cm}^{-2}\right]$ & $\mathrm{FF}[\%]$ & $\mathrm{PCE}$ a) $[\%]$ \\
\hline & 0.89 & 21.04 & 67.78 & 12.69 \\
& $(0.89 \pm 0.01)$ & $(20.72 \pm 0.38)$ & $(67.24 \pm 0.51)$ & $(12.48 \pm 0.12)$ \\
80 & 0.89 & 21.39 & 70.71 & 13.46 \\
& $(0.89 \pm 0.01)$ & $(21.01 \pm 0.37)$ & $(70.02 \pm 0.67)$ & $(13.36 \pm 0.08)$ \\
100 & 0.89 & 21.66 & 70.89 & 13.67 \\
& $(0.89 \pm 0.01)$ & $(21.24 \pm 0.40)$ & $(70.26 \pm 0.46)$ & $(13.45 \pm 0.18)$ \\
\multirow{2}{*}{$\mathbf{1 2 0}$} & $\mathbf{0 . 8 8}$ & $\mathbf{2 2 . 1 2}$ & $\mathbf{7 2 . 7 9}$ & $\mathbf{1 4 . 1 7}$ \\
& $\mathbf{( 0 . 8 8} \pm \mathbf{0 . 0 1})$ & $\mathbf{( 2 1 . 6 9 \pm \mathbf { 0 . 3 4 } )}$ & $\mathbf{( 7 2 . 1 5} \pm \mathbf{0 . 5 3 )}$ & $\mathbf{( 1 4 . 0 1} \pm \mathbf{0 . 1 4})$ \\
130 & 0.88 & 21.84 & 72.02 & 13.84 \\
& $(0.88 \pm 0.00)$ & $(21.56 \pm 0.33)$ & $(71.54 \pm 0.45)$ & $(13.67 \pm 0.13)$ \\
\hline
\end{tabular}

a) The average values were obtained from over 12 devices.
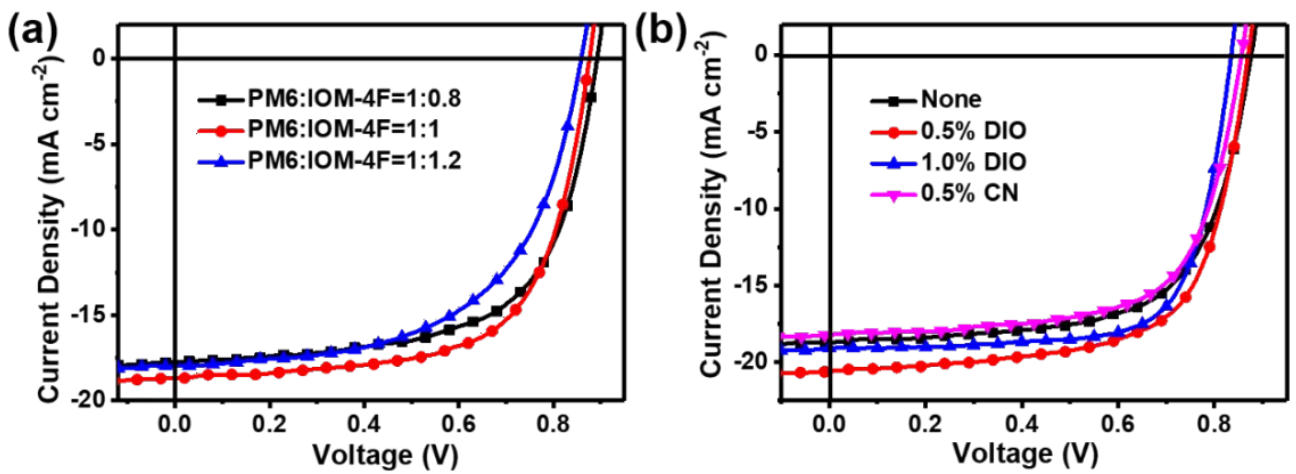

Figure S14. a) $J-V$ curves of PM6:IOM-4F based devices with different D/A ratios; b) $J-V$ curves of devices based on PM6:IOM-4F=1:1 films with different additive.

Table S4. The optimized photovoltaic parameters of devices based on PM6:IOM-4F with different $\mathrm{D} / \mathrm{A}$ ratios.

\begin{tabular}{ccccc}
\hline $\mathrm{D} / \mathrm{A}$ & $V_{\mathrm{OC}}[\mathrm{V}]$ & $J_{\mathrm{SC}}\left[\mathrm{mA} \mathrm{cm}^{-2}\right]$ & $\mathrm{FF}[\%]$ & $\mathrm{PCE}{ }^{\mathrm{a}}[\%]$ \\
\hline \multirow{2}{*}{$1: 0.8$} & 0.89 & 17.74 & 63.70 & 10.06 \\
& $(0.89 \pm 0.01)$ & $(17.34 \pm 0.36)$ & $(63.21 \pm 0.47)$ & $(9.95 \pm 0.08)$ \\
$\mathbf{1 : 1}$ & $\mathbf{0 . 8 8}$ & $\mathbf{1 8 . 6 8}$ & $\mathbf{6 5 . 1 5}$ & $\mathbf{1 0 . 7 1}$ \\
& $\mathbf{( 0 . 8 8} \pm \mathbf{0 . 0 1 )}$ & $\mathbf{( 1 8 . 3 4} \pm \mathbf{0 . 3 2})$ & $\mathbf{( 6 4 . 6 4} \pm \mathbf{0 . 3 7})$ & $\mathbf{( 1 0 . 5 4} \pm \mathbf{0 . 1 6 )}$ \\
$1: 1.2$ & 0.86 & 17.97 & 57.72 & 8.92 \\
& $(0.86 \pm 0.01)$ & $(17.49 \pm 0.42)$ & $(57.21 \pm 0.46)$ & $(8.74 \pm 0.09)$ \\
\hline
\end{tabular}

a) The average values were obtained from 12 devices.

Table S5. The optimized photovoltaic parameters of devices based on PM6:IOM$4 \mathrm{~F}(1: 1)$ blends using different additives. 


\begin{tabular}{ccccc}
\hline Additive & $V_{\mathrm{OC}}[\mathrm{V}]$ & $J_{\mathrm{SC}}\left[\mathrm{mA} \mathrm{cm}^{-2}\right]$ & $\mathrm{FF}[\%]$ & $\mathrm{PCE}^{\mathrm{a}}{ }^{2}[\%]$ \\
\hline \multirow{2}{*}{ none } & 0.88 & 18.68 & 65.15 & 10.71 \\
& $(0.88 \pm 0.01)$ & $(18.34 \pm 0.32)$ & $(64.64 \pm 0.37)$ & $(10.54 \pm 0.16)$ \\
$\mathbf{0 . 5 \%}$ DIO & $\mathbf{0 . 8 7}$ & $\mathbf{2 0 . 5 9}$ & $\mathbf{6 6 . 6 1}$ & $\mathbf{1 1 . 9 3}$ \\
& $\mathbf{( 0 . 8 7} \pm \mathbf{0 . 0 1 )}$ & $\mathbf{( 2 0 . 2 9} \pm \mathbf{0 . 2 4})$ & $\mathbf{( 6 6 . 1 4} \pm \mathbf{0 . 4 6 )}$ & $\mathbf{( 1 1 . 8 2} \pm \mathbf{0 . 1 2})$ \\
$1.0 \%$ DIO & 0.84 & 19.09 & 71.75 & 11.51 \\
& $(0.85 \pm 0.01)$ & $(18.65 \pm 0.35)$ & $(71.19 \pm 0.48)$ & $(11.19 \pm 0.24)$ \\
$0.5 \% \mathrm{CN}$ & 0.86 & 18.35 & 66.45 & 10.49 \\
& $(0.86 \pm 0.00)$ & $(18.01 \pm 0.31)$ & $(66.02 \pm 0.45)$ & $(10.21 \pm 0.27)$ \\
\hline
\end{tabular}

a) The average values were obtained from over 12 devices.

Table S6. The optimized photovoltaic parameters of PM6:IOM-4F(1:1) blends based devices using different thermal annealing temperatures (TATs) with $0.5 \%$ volume DIO.

\begin{tabular}{ccccc}
\hline TAT $\left[{ }^{\circ} \mathrm{C}\right]$ & $V_{\mathrm{OC}}[\mathrm{V}]$ & $J_{\mathrm{SC}}\left[\mathrm{mA} \mathrm{cm}^{-2}\right]$ & $\mathrm{FF}[\%]$ & $\mathrm{PCE}^{\text {a) }}[\%]$ \\
\hline- & 0.87 & 20.59 & 66.61 & 11.93 \\
& $(0.87 \pm 0.01)$ & $(20.29 \pm 0.24)$ & $(66.14 \pm 0.46)$ & $(11.82 \pm 0.12)$ \\
80 & 0.86 & 20.84 & 68.99 & 12.36 \\
& $(0.86 \pm 0.01)$ & $(20.54 \pm 0.32)$ & $(68.24 \pm 0.64)$ & $(12.22 \pm 0.09)$ \\
100 & 0.86 & 21.32 & 70.15 & 12.86 \\
& $(0.86 \pm 0.01)$ & $(20.94 \pm 0.32)$ & $(69.39 \pm 0.66)$ & $(12.64 \pm 0.15)$ \\
\multirow{1}{*}{$\mathbf{1 2 0}$} & $\mathbf{0 . 8 6}$ & $\mathbf{2 1 . 6 6}$ & $\mathbf{7 2 . 0 0}$ & $\mathbf{1 3 . 4 1}$ \\
& $\mathbf{( 0 . 8 6} \pm \mathbf{0 . 0 1})$ & $\mathbf{( 2 1 . 2 3} \pm \mathbf{0 . 4 6 )}$ & $\mathbf{( 7 1 . 4 8} \pm \mathbf{0 . 5 6 )}$ & $\mathbf{( 1 3 . 2 0} \pm \mathbf{0 . 1 7})$ \\
130 & 0.86 & 21.43 & 71.63 & 13.20 \\
& $(0.86 \pm 0.01)$ & $(21.03 \pm 0.39)$ & $(71.14 \pm 0.46)$ & $(12.94 \pm 0.19)$ \\
\hline
\end{tabular}

a) The average values were obtained from over 12 devices.

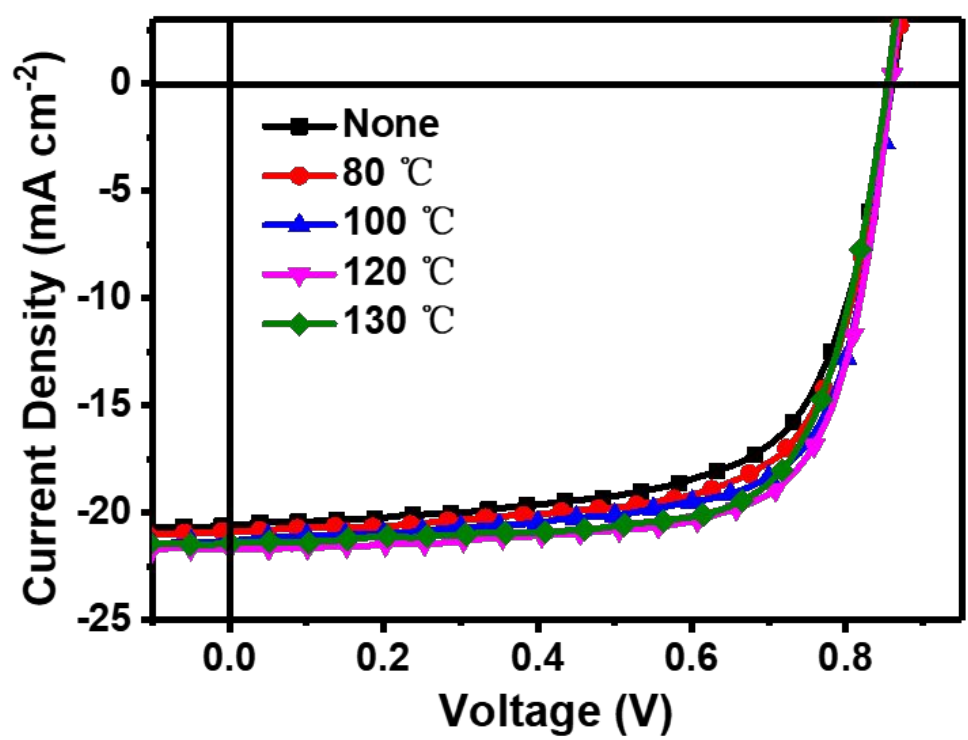


Figure S15. $J-V$ curves of devices based on PM6:IOM-4F $=1: 1$ at different thermal annealing temperature with $0.5 \%$ volume DIO.

Table S7. Hole and electron mobilities of the blend films

\begin{tabular}{llll}
\hline Blend Film & $\mu_{\mathrm{h}}\left[\mathrm{cm}^{2} \mathrm{~V}^{-1} \mathrm{~s}^{-1}\right]$ & $\mu_{\mathrm{e}}\left[\mathrm{cm}^{2} \mathrm{~V}^{-1} \mathrm{~s}^{-1}\right]$ & $\mu_{e} / \mu_{\mathrm{h}}$ \\
\hline PM6:IM-4F & $5.08 \times 10^{-4}$ & $5.18 \times 10^{-4}$ & 1.02 \\
PM6:IOM-4F & $4.18 \times 10^{-4}$ & $4.76 \times 10^{-4}$ & 1.14 \\
PM6:IT-4F & $5.43 \times 10^{-4}$ & $7.34 \times 10^{-4}$ & 1.35 \\
\hline
\end{tabular}
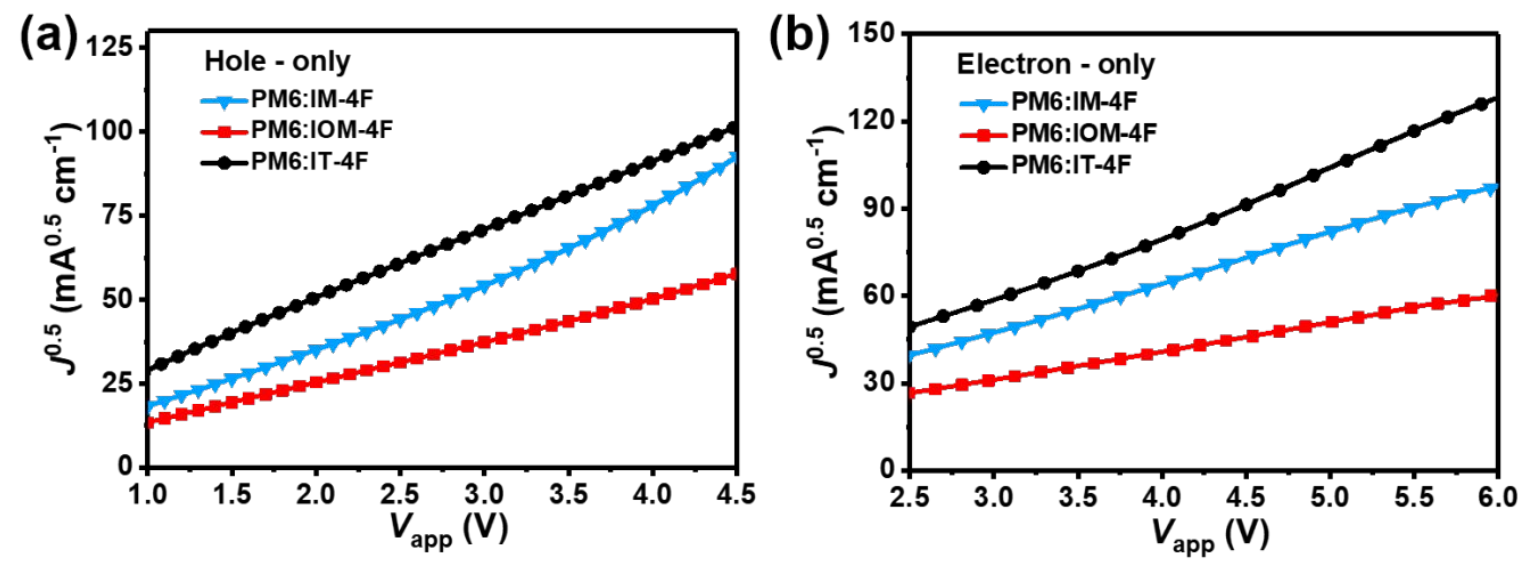

Figure S16. Hole and electron mobilities of blend films. 


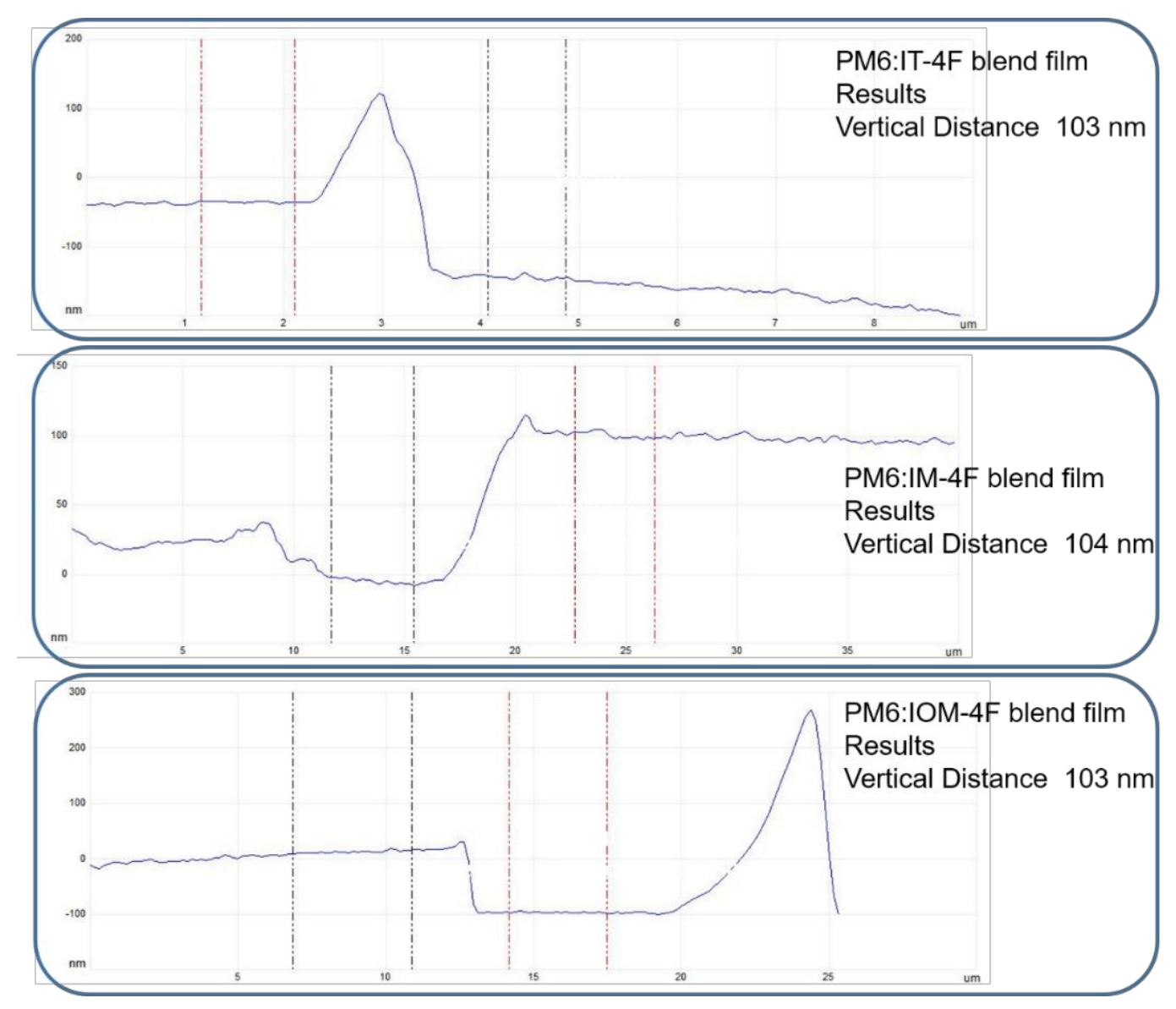

Figure S17. Thickness of the blends films.
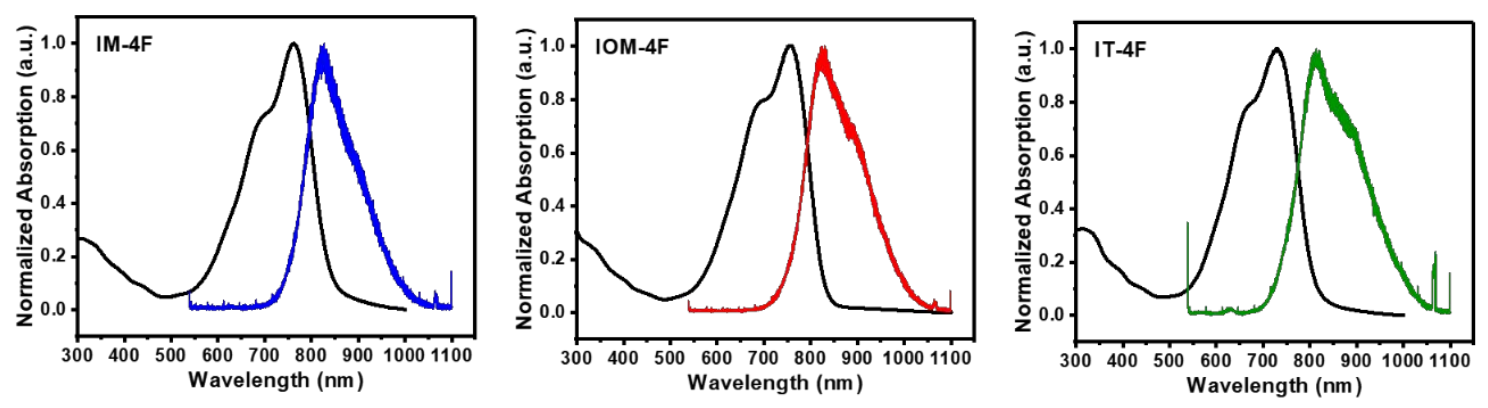

Figure S18. Normalized emission and absorption spectra.

\section{REFERENCES}

(1) Henssler, J. T.; Zhang, X.; Matzger, A. J. Thiophene/thieno[3,2-b]thiophene cooligomers: fused-ring analogues of sexithiophene. J. Org. Chem. 2009, 74, 91129119.

(2) Burke, M. J.; Nichol, G. S.; Lusby, P. J. Orthogonal Selection and Fixing of Coordination Self-Assembly Pathways for Robust Metallo-organic Ensemble Construction. J. Am. Chem. Soc. 2016, 138, 9308-9315. 
